\title{
Invited editorial for the inaugural issue of Geospatial Health
}

\author{
Barnett L. Cline \\ Blanco, Texas 78606, USA
}

Keywords: remote sensing, epidemiology, disease control, arthropod-borne viruses.

In 1970, when I published "New Eyes for Epidemiologists: Aerial Photography and Other Remote Sensing Techniques" (Cline, 1970) in the American Journal of Epidemiology little could I imagine that 20 years later the first International Conference on Applications of Remote Sensing to Epidemiology and Parasitology would be held (Louisiana State University, Baton Rouge, June 67, 1990), nor that Geospatial Health would make its debut in 2006. When I wrote this paper, my first, I was a doctoral student in epidemiology at the University of California, Berkeley. The great arbovirologist/epidemiologist William C. Reeves was my faculty mentor, overseeing my research on the distribution in humans of neutralizing antibodies to vesicular stomatitis virus in Central America and Panama (Cline, 1973, 1976). Over $50 \%$ of the human population had serologic evidence of past infection, yet the means of transmission was unknown. Among possible determinants of transmission I wanted to classify the ecological characteristics of the hundreds of study communities, but these data were only available in very crude form. Hoping that aerial photographs of the communities would offer a more precise means of ecological classification, I enrolled in the course "Aerial Photo Interpretation" offered by the University of California's Department of Geography and taught by Robert N. Colwell, a

Corresponding author:

Barnett L. Cline

Professor Emeritus, Tulane University

Current address: P.O. Box 1477

Blanco, Texas 78606, USA

E-mail: blchome@moment.net leading authority on remote sensing of natural resources. I recall my fascination in learning from Professor Colwell about the wide range of remarkable applications of remote sensing in agriculture, forestry, hydrology, oceanography, range and wildlife management, geography and cartography. A dramatic example, I learned that early disease and stress in trees and other crops could be detected remotely before evidence was apparent from ground level inspection!

From my epidemiology studies I was beginning to appreciate that while most pathogens transmitted in a human-to-human cycle are not constrained geographically, zoonotic and insect-transmitted diseases, in contrast, tend to be focal in distribution, with their maintenance cycles dependent upon exacting ecological conditions. The term "landscape epidemiology", coined by the Soviet Academician E.N. Pavlovsky (1884-1965), provided the spark which led me to link remote sensing with epidemiology, and to begin speculating about how epidemiology might be added to the list of disciplines for which remote sensing provided a powerful tool for investigation and disease control. Pavlovsky and his colleagues developed the concept of "disease nidality", i.e. that certain diseases such as old world leishmaniasis and tick-borne encephalidities, occupy ecological niches much in the same manner as any living thing has a characteristic niche in nature (Pavlovsky, 1966). Russian Spring and Summer Encephalitis (RSSE), associated with the taiga forests of Siberia, is another example. This concept was expanded by Western investigators such as Ralph Audy at the University of California, San Francisco, who applied it to the 
study of scrub typhus in Malaysia. Audy also explored the impact of human activity on agriculture and the peridomestic environment, and how this activity created conditions which enhance transmission of many vector-borne and zoonotic diseases. I was introduced to these powerful concepts during my graduate studies.

In the 1970 paper, I wrote "In epidemiology we are concerned with associations between indices of disease occurrence and characteristics of man and his environment. Remote sensing offers an opportunity to measure many of these characteristics from a novel vantage point, and to record them in a convenient, permanent form." These words are no less true today; indeed the capacity to collect, store, manipulate and interpret remotely-derived data has expanded exponentially because of multiple technological advances and increasingly powerful computers. I ended my speculation with "In short, there may be a whole spectrum of applications awaiting the imaginative investigator". The field remains in its infancy.

In the early 1970s, while at the CDC's San Juan Laboratories in Puerto Rico, I collaborated with NASA to assess the usefulness of near infra-red photography (from aircraft platforms) for identifying breeding sites of Biomphalaria glabrata, an intermediate host of Schistosoma mansoni. Our hope was to take advantage of an association between certain plants and snail breeding sites to facilitate mapping of these sites. This, it was thought, might permit elimination of the sources of re-introduction of $B$. glabrata into the streams where transmission to humans took place. For reasons beyond the scope of this communication, the remote-derived data in this example did not translate into improved disease control and I feel a lingering guilt that I never published the negative findings. What have these several decades taught us? I suggest a few important lessons learned:

(i) first, care should be taken not to oversell the potential applications of remote sensing for disease control. To do so damages credibility, something which occurred in the early and mid-1970s in the push for congressional support for investment in space technology. Impressive as computer-enhanced, remotelysensed images of the earth's surface may be, much research remains to be done before disease control authorities will be convinced of the practical application of remote sensing. It should be remembered that it is still primarily a research tool;

(ii) second, many tend to be driven by the assumption that greater resolution of remotely-sensed imagery translates into greater value as a predictor of disease activity. I believe it can be counterproductive to become consumed with the quest for greater resolution per se. For example, a remotely-sensed feature such as a diurnal temperature difference $(\mathrm{dT})$, derived from thermal scanning radiometry, reflects surface and subsurface moisture on a crude scale [averaging $10 \mathrm{~km}$ square]. $\mathrm{dT}$ values were highly predictive of the distribution of human Bancroftian filariasis in the southern Nile Delta (Thompson et al., 1996). Such a measure is broadly integrative and low in resolution, but evidence is lacking that features with higher resolution are equally predictive of disease transmission;

(iii) third, and most important from my perspective, is the critical need for building collaboration between researchers engaged in comprehensive, long-term community-based research and experts in remote sensing and geographic information systems (GIS).

Because of the natural variation in transmission levels of pathogens, disease occurrence and other determinants such as vector and/or reservoir host populations must be monitored over a period of years before meaningful associations with remotely-derived imagery can be established with confidence. Investigators with remote sensing and GIS expertise are urged to seek partners with favorable prospects of secure funding, and who have a good track record of longitudinal field studies in defined areas for which appropriate remotely- 
sensed data are available. Opportunities for ideal "marriages" are limited, require active searching in both directions, and depend upon a genuine spirit of multi-disciplinary research partnership. I believe Geospatial Health can play a crucial role in bringing together potential partnerships.

A final challenge is for research to move beyond demonstrating associations between images and vector or reservoir abundance. Because disease control is the ultimate objective, research must also demonstrate that remotely-derived data offer distinct advantages over alternate approaches to data collection. I am confident that remote sensing will increasingly help elucidate the epidemiology of diseases which threaten us, and will facilitate their prevention and control. And I am hopeful that one day soon remote sensing will lead to public heath successes which rival the forestry example in which a forest can be saved by early recognition of one sick tree among thousands.

\section{References}

Cline BL, 1970. New Eyes for Epidemiologists: Aerial Photography and other Remote Sensing Techniques. Am J Epidemiol 92, 85-89.

Cline BL, 1973. The Distribution of Neutralizing Antibodies to Vesicular Stomatitis Virus in Central America and Panama. Ph.D. Dissertation, University of California, School of Public Health.

Cline BL, 1976. Human Infections with Vesicular Stomatitis Virus in Central America and Panama: Ecological Associations. Am J Trop Med Hyg 25, 875-883.

Pavlovski EN, 1966. Natural nidality of transmissible diseases, with special reference to the landscape epidemiology of zooanthroponoses. University of Illinois Press, Urbana, 261 pp.

Thompson DF, Malone JB, Harb M, Faris R, Huh OK, Buck AA, Cline BL, 1996. Bancroftian filariasis distribution and diurnal temperature differences in the southern Nile delta. Emerg Infect Dis 2, 234-235. 